\title{
Therapeutic approach to complicated grief - an example of group psychotherapy in psychiatric patients
}

WORLD

PSYCHIATRIC ASSOCIATION
J.I. Soares ${ }^{1}$, S. Pinto ${ }^{1}$, A.F. Oliveira ${ }^{2}$, R. Curral ${ }^{1}$, R. Coelho ${ }^{1}$.

${ }^{1}$ Centro Hospitalar e Universitário São João, Clínica de Psiquiatria e Saúde Mental, Porto, Portugal.

2Universidade de Aveiro, Departamento de Educação e Psicologia da Universidade de Aveiro, Aveiro, Portugal.

\section{INTRODUCTION}

- Complicated Grief (CG) affects 7-10\% of the grieving individuals in the general population - maintenance of acute grief symptoms for longer than expected or with excessive intensity, with no improvement of suffering $[1,2]$. The incidence of this condition is much higher in psychiatric patients, reaching $70 \%$ in most samples. These individuals present many risk factors for such condition, demanding a particular attention and treatment approach.

- Most studies have shown that pharmacological treatment may help relieving depressive and anxiety symptoms, although they do not promote a consistent improvement of the grieving scenario. Several meta-analyses have recognized different psychological interventions as effective in dealing with the loss, decreasing psychological suffering and promoting adaptation. It is accepted that the benefits of the intervention overcome any possible harm.

Aim:

- To evaluate the impact of a group intervention (12 sessions) in pharmacologically stabilized psychiatric patients presenting with CG.

\section{MATERIALS AND METHODS}

\section{Participants:}

- 19 experimental group participants (EG) (17 female and 2 male); age: 29 71 years old $(\mathrm{M}=49.32$ e $\mathrm{DP}=12.02)$

- Marrital Status: single $10.5 \%(n=2)$, Married $26.3 \%(n=5)$, Widowed 47.4\% ( $n=9)$, Divorced 10.5\% ( $n=2)$, Other 5.3\% ( $n=1)$

- 11 control group participants (CG) (10 female and 1 male); age: 31 - 70 years old $(M=53.09$ e $D P=10.97)$

Evaluation instruments:

- Clinical Interview (Silva \& Rocha, 2009)

- ICG - Complicated Grief Inventory (Prigerson et al., 1995)

- IES-R - Impact of Events Scale - Revised (Weiss \& Marmar, 1997; adapted by Rocha et al., 2006)

- BDI - Beck Depression Inventory (Beck, 1961)

- EAS - Social Support Scale (Matos \& Ferreira, 1999)

\section{RESULTS}

- Relation do the deceased person: father/mother $26.3 \%$; spouse $31.6 \%$; son/daughter $42.1 \%$

- Frequency of Psychiatric Disorders:

\begin{tabular}{lcccrr}
\hline & \multicolumn{2}{c}{ I $^{\text {st }}$ Assessment } & \multicolumn{2}{c}{ 2 $^{\text {nd }}$ Assessment } \\
\hline & With & Without & \multicolumn{1}{l}{ With } & Without \\
Depression & 17 & 2 & 14 & 5 \\
Complicated Grief & 19 & 0 & 19 & 0 \\
Post-traumatic stress & 17 & 2 & 15 & 4 \\
\hline
\end{tabular}

- There were significant differences between pre and post intervention assessement in the EG, with decrease of depression and posttraumatic stress levels

\begin{tabular}{lcccccc}
\hline & \multicolumn{1}{c}{$\begin{array}{c}\text { Ist Assessment } \\
(\mathbf{n}=1 \text { 19) }\end{array}$} & \multicolumn{4}{c}{$\begin{array}{c}\mathbf{2}^{\text {nd }} \\
\text { Assessment } \\
(\mathbf{n}=1 \mathbf{1 9})\end{array}$} \\
\cline { 2 - 8 } & $\mathrm{M}$ & $\mathrm{DP}$ & $\mathrm{M}$ & $\mathrm{DP}$ & $\mathrm{T}$ & $\mathrm{P}$ \\
\hline Depression & 23.95 & $\mathrm{I} 1.5 \mathrm{II}$ & 16.26 & 10.088 & 5.498 & .000 \\
Complicated Grief & 58.00 & 10.094 & 53.68 & 12.211 & 1.572 & .133 \\
Post-traumatic stress & 49.68 & 13.825 & 39.26 & 14.082 & 3.958 & .001 \\
\hline Social Support & 30.58 & 7.552 & 30.84 & 8.375 & -.148 & .884 \\
\hline
\end{tabular}

- There were no significant differences between the two groups regarding the psychopathology presented.

\section{Group Intervention}

- Closed group; with sessions every fortnight/ duration $\approx 90$ min.; cognitivebehavioral approach;

- Intervention based on:

- Development of coping strategies, to deal with the grief context;

- Promoting a proper setting to share personal experiences;

- Promoting mutual help between group member, enhancing the cohesion, authenticity and change.

\section{Procedure}
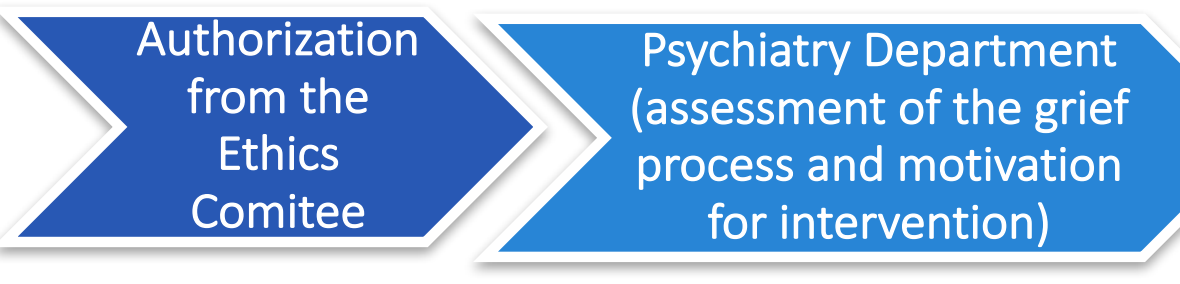

\section{DISCUSSION}

- The intervention prooved to be effective in this population, particularly regarding depression and post-traumatic stress.

- The comorbidity with psychiatric disorders is a risk factor for complicated grief. Moreover, complicated grief is frequently diagnosed as depression or post-traumatic stress disorder.

- Therefore, the significant decrease in depression and post-traumatic stress levels in the intervention group, could promote a relief of the suffering associated with the beneficial group effect.

- Our results corroborate studies to date (e.g., [5]),. reporting a positive effect at the intervention levels, increasing significantly over the long term.

- We can conclude that group intervention and the all therapeutic factors that emerged from it, facilitaded the process and acceptance to the loss and adaptation to the new reality of its participants. 